\title{
Emotional Intelligence as a Correlate of Social and Academic Adjustment of First Year University Students in South East GEO- Political Zone of Nigeria
}

\author{
Janet Ngozi Igbo $^{1 *}$, Ruth N. Nwaka ${ }^{2}$, Felicia Mbagwu ${ }^{3}$, Dan Mezieobi ${ }^{4}$ \\ 1,2 Department of Educational Foundations, University of Nigeria, Nsukka, NIGERIA \\ ${ }^{3}$ Department of Adult Education, University of Nigeria, Nsukka, NIGERIA \\ ${ }^{4}$ Department of Social Science Education, University of Nigeria, Nsukka, NIGERIA \\ *Corresponding Contact: \\ Email: janetigbo@yahoo.com
}

\begin{abstract}
The ability of passing through secondary school to the university level can be a stressful experience for many new undergraduate students. One of the challenges that they are confronted with is the need to develop their emotional intelligence and to adjust to the new environment. The present study was carried out to find out how emotional intelligence correlates with social and academic adjustment of first -year university students. A total of 200 first -year students from four functional faculties of education in federal universities in South-east geo-political zone of Nigeria with an objective to find out how emotional intelligence correlates with social and academic adjustment of first-year university students. The researchers applied Pearson product moment correlation in analyzing the data and for answering the research questions and Regression analysis for testing the two research hypotheses at 0.05 level of significance. Results of the study showed that emotional intelligence correlated positively with social and academic adjustment of first- year students and that emotional intelligence significantly predicted first -year students' social and academic adjustment in school.
\end{abstract}

Keywords: Adjustment, Emotions, Emotional Intelligence, Social adjustment, Academic adjustment

How to Cite: Igbo JN, Nwaka RN, Mbagwu F and Mezieobi D. 2016. Emotional Intelligence as a Correlate of Social and Academic Adjustment of First Year University Students in South East GEO-Political Zone of Nigeria ABC Journal of Advanced Research, 5, 9-20.

This article is is licensed under a Creative Commons Attribution-NonCommercial 4.0 International License. Attribution-NonCommercial (CC BY-NC) license lets others remix, tweak, and build upon work non-commercially, and although the new works must also acknowledge \& be non-commercial.

\section{INTRODUCTION}

Students transiting from secondary school to university are faced with a lot of challenges as modification and growth process take a lot of effort and also require hard work. When 
students graduate from secondary schools into the universities, the students usually face unfamiliar experiences and more demanding social and academic environment (Mudhovozi, 2012). This transition usually occurs with new responsibilities and challenges. Generally, at the university level, first-year students find that competition is more intense especially as the lecturers use different teaching styles in the process of teaching. Besides, there is much work, and the population of the students is greater in number with more assignments. Enochs and Renk (2006) are of the opinion that students transiting from secondary schools to universities are expected to study hard, change their study habits and rearrange their priorities to adjust properly.

Emotions refer to the energies or forces that initiate activity in individuals (Brody, 2004). Individuals are creatures of feelings, and this brings about aspirations. Students' emotion fundamentally involves physiological arousal, expressive behavior and conscious experiences associated with mood, temperament, motivation, personality and disposition. Students behave in certain ways as a result of their emotional state, such as crying, fighting or fleeing (Roberts, Zeidner \& Matthews, 2001). These transitional challenges are dealt with differently by students based on their emotional intelligence.

The originators of emotional intelligence are Mayer and Salovey (1990) in their attempt to develop a scientific measure for knowing the differences between individuals' ability in the areas of emotions. In spite of their effort, evidence indicated that emotional intelligence was popularized by Goleman (1995), who pulled together different personality traits such as motivation, persistence, warmth, social skills and empathy in the process of his explanation of emotional intelligence. According to Mangal (2010), the most explanation or definition of emotional intelligence is the definition given by Mayer and Salovey (1997) which stated that emotional intelligence is seen as the capacity to reason with emotion in four ways that is to perceive emotion, to integrate it in thought, understand and manage it. In this definition, individual differences are considered in relation to handling emotions, having the knowledge of one's feelings, using it to solve problems in taking decision by dealing with emotions when it has to do with the individuals and their environment.

According to Haute Schlage R as cited by Mangal (2010), to be emotionally intelligent involves being proficient in the four A's of emotional intelligence that is Awareness, Acceptance, Attitude and Action. Awareness has to do with knowing what one is feeling and when the feeling appears. Acceptance involves the individual believing that emotions are biological process that takes place in the body with the connection of the brain that at times may not be rational. That is feeling emotions without passing judgment on it. Attitudes which involve beliefs attached to the individuals feelings. Lastly is action which has to do with the behaviour taken based on ones emotions and attitude towards things. This implies that for one to be regarded as emotionally intelligent, the individual needs to possess the ability to understand his or her emotions and people's reactions, to realize that at times one can be irrational in expressing emotions and to have the capability to form attitudes and at the same time be able to manipulate these attitudes.

Emotional intelligence means, how intelligently individuals/students can control their emotions. Emotional intelligence is a self-perceived ability and skill to identify, assess and regulate the emotions of one and others (Petrides \& Furnham, 2006). This ability helps students to be in control so as to adjust in the school environment. Therefore, it refers to the capacity for recognizing our feelings and those of others, for motivating ourselves and for managing emotions in the process of our relationships with others. Madhavi, and Vijayalaxmi (2010) maintained that emotional intelligence is one's ability to perceive 
emotions, integrate emotion, facilitate thought, and understand emotion and to regulate emotions in promoting personal growth. When such competence is lacking in students, it becomes difficult handling cognitive activities and directing emotions in both oneself and others. It is therefore necessary for students to strive to be in charge of their sentiments (Collins, Welsh \& Furman, 2009). This creates psychological turbulence as these students adjust in their new found academic and social environments.

Mayer, Salovey and Caruso (2004) see emotional intelligence as the capacity to reason about emotions and the ability to enhance thinking. It includes the abilities to accurately perceive feelings. To assess and generate emotions so as to assist thought. It becomes necessary to understand emotional knowledge to regulate emotions and to promote intellectual growth. For Pelletteri (2002), emotional intelligence is an individual's ability to accurately perceive reality. To understand and regulate his/her emotional responses and to adapt and respond to others. Hein (2007) sees emotional intelligence as the ability, capacity, skill or potential to feel, use, communicate, recognize, remember, describe, identify, learn, manage, understand and explain emotions. Robbins and Judge (2009) opined that emotional intelligence is a person's ability to be self-aware, recognizing his or her passions when experiencing them and detect emotions in others as well as manage emotional cues and information. Segal and Smith (2013) see emotional intelligence as the ability to identify, use, understand and handle feelings confidently to ease stress, overcome challenges, empathize with others, and defuse conflict. Intelligence has to do with students' ability to perceive, control and evaluate emotion that is usually helpful in assisting students to succeed in school.

Emotional intelligence has been conceptualized in literature both as a relatively enduring trait and an ability to adaptively recognize, understand, manage, harness emotions both in self and others, and to use emotion to facilitate cognitive processing (Mayer, Salovey \& Caruso, 2002; Petrides \& Furnham, 2006 \& Santrock, 2008). Van Rooy and Viswesvaram (2004) are of the view that emotional intelligence is a talent, that builds individuals to acquire, acknowledge, articulate, grasp and assess his own and others emotions so as to take actions to cope successfully with environmental needs and pressures. Emotional intelligence helps a person to understand his or her attitudes while in contact with others. For Mayer, Salovey and Caruso (2004), the emotionally intelligent person is skilled in four areas that include; identifying emotions, using emotions, understanding emotions and regulating emotions. Emotional skill development is helpful in assisting students to succeed in school. Therefore, university students who are skilled in these areas not only adjust well in school academically but also in their social interaction with people.

Emotional intelligence is the ability to monitor a person's feelings and that of others to discriminate among individuals and use this information to guide their thinking and actions (Grewal \& Salovey, 2005). Emotional intelligence plays a powerful role in peoples' lives and helps in understanding and controlling emotions and using them in a more positive way. According to Mudhovozi (2012), new students are anxious as they adjust to academic, social and personal challenges that the university presents. Some people handle adjustment issues clearly while others fail to cope with these changes in the institution. This calls for concern as adjustment to the university environment is regarded as an important factor in predicting the school outcome Most times modification is based on how emotionally intelligent the individual is. Students tackle the challenges they see in institutions differently, and this prompted the researchers to ascertain if there is a correlation between first- year students emotional intelligence with their academic and social adjustment. 
Adjustment is the process of adapting to something or an environment. According to Parker, Rubin, Earth, Wojslawowics and Buskirk (2006), an adjustment is the behavioral process that individuals acquire for balance to enable them to solve their problems.A string of modification starts when needs arise and ends when it is solved. Santrock (2008) maintained that adjustment refers to a continuous process by which a person changes his own behavior or tries to change the environment or bring changes in both to produce a satisfactory relationship with his environment. Lopes and Salovey (2004) and Raju and Rahamtulla (2007) are of the opinion that adjustment is the individual's ability to fulfill his/her psychological needs and self-acceptance as well as enjoying life without any type of conflict. Adjustment entails accepting social activities or participation in social activities. It equally implies that adjustment is the individual's meeting of his/her psychological demands and accommodating oneself depending on the situation one finds himself.

Adjustment is a process by which individuals attempt to maintain a level of psychological and physiological equilibrium (Tuckman \& Monetti, 2010). Boulter (2002) opined that adjustment is not a one-way process in which the individual conforms to the duties and requirements of others, but a two-way process because personal needs and environmental needs have to be modified. For the fact that life is not stable the capability to change one's behavior appropriately is an essential ingredient of adjustment. Students' developmental and academic challenges are among the issues that require modification. Every individual, old and young, is confronted with the problem of adjustment. Students' academic social adjustments are of great concern to educationists and health practitioners. The importance could be as a result of the challenges that university students face in school. Burgess, Crocombe, Kelly and Seet (2009) maintained that failure to meet the wider academic and social problems confronting students during the period from secondary school to university has great impacts on the learning outcome, emotional intelligence and their world view.

Wang, Chen, Zhau and Yan (2006) indicate that academic adjustment is dealing with various educational demands of the school. As new students move from one class to another, they are required to adapt to an environment that not only changes in respect to academic requirements but also in respect to personal independence. Researches show that students' inability to adjust to environmental changes, their inappropriate subject choice and developmental issues are some major causes of withdrawal from school leading to maladjustment (Edward, 2003; Kumar, 2006). Adjustment to school could be an important predictor of individual's educational progress and emotional intelligence. Academic adjustment describes the well-being of students as they settle into school and is specifically measured by their perceptions, or attitudes towards school, their level of anxiety, behavior in the classroom and performance on tasks. Boulter (2002) defines academic adjustment of the individual as the ability to fit, and adapt to accommodate himself to satisfy his educational needs. Students experience changes due to the pressure to perform well and be successful after graduation - either for higher studies or getting a job. Students from federal institutions particularly, first-year in the south-east geo-political zone in Nigeria are faced with these challenges of adjusting as they progress in their academic pursuit. These problems continue to manifest in different forms and need to be addressed before they get out of hand.

Kupersmidt and DeRosier (2004) maintained that first-year students represent the main context in which many developmental adjustment problems will be addressed. Students just entering the university environment may deal with autonomy issues in response to 
the school environment requiring more self-reliance from them. Students are confronted with adjustment problems, such as the stress associated with moving into the tertiary institution, changing lecturers, meeting the deadline for assignments and term papers, among others. This led the researchers to investigate if there is any relationship between emotional intelligence of first-year university students and their academic and social adjustment.

\section{THEORETICAL FRAMEWORK}

Salovey and Mayer (1997) proposed a model that sees emotional intelligence as the ability to perceive emotion, integrate it and, understand feelings, and the capability to regulate or handle emotions to promote emotional and intellectual growth. This model comprises four aspects of ability that include perception, assimilation or integration, understanding and regulation or management of emotions. The theorists maintained that emotional view consisted of the capability to perceive emotions of self and others. The accommodation of feelings is the process of generating emotions necessary to communicate with others and use them in cognitive processes. Emotional understanding is the possibility to understand emotional information, how emotions combine and shift across time and the ability to appreciate the emotional meaning. Emotional regulation means the capability to be clear to emotions, monitoring stay open to feelings, and to monitor and regulating ones and others emotions to promote the understanding of intellectual and personal growth. The process of regulating emotions is built on the individuals' competencies of these aspects of emotional intelligence. This model emphasized that emotions can be used to guide logical thinking, goal-oriented actions, and enhance rationality. This means that students that lack emotional intelligence might as well lack the ability to adjust in learning environment as well as their personal relationship among peers.

Bandura (1977) proposed a Social cognitive learning theory with the major highlights that much of human learning occurs in a social environment. Bandura maintained that by observing others, individuals gain knowledge of the environment. They equally learn acceptable and appropriate behaviour by observing models and the consequences of modeled behaviours and they act by their beliefs concerning the expected outcomes of actions. Students adjust in the university environment socially by observing and modeling desired attitudes that are observed around them. Bandura maintained that the actions of others influenced behaviour at any point in time. Therefore, first-year university students usually found themselves in a new environment, and there is the need for them to adjust to desirable behaviours for an adequate academic requirement. Adjustment can only be acquired by students' ability to model attitudes of other students around them.

\section{Review of Related Empirical Studies}

In a study carried out on emotional intelligence and social adaptation among students by Shakuntala and Santoch (2011) in Hisar district of Haryana to investigate the emotional intelligence level of school children and the relationship on their adjustment. The researchers made use of 120 students (between 16 - 18 years). The finding indicated that emotional intelligence was in relationship to adjustment of children. The study also revealed that rural respondents were slightly better in their emotional intelligence than the urban respondents.

Adeyemo (2004) conducted a study on the buffering effect of emotional intelligence on the adjustment of secondary school students in transition in Ibadan city, Nigeria with the 
specific objective of investigating the relationship between emotional intelligence and adjustment of primary and secondary students. Using 200 fresh secondary school students, the researcher administered emotional intelligence Questionnaire (EIQ) designed by Schutte, Malloff, Hall, Haggertry, Copper, Golden and Dornheim (1998) to assess emotional intelligence and section $\mathrm{j}$ of Adolescent personal data inventory (APDI) by Akinboye (2003) to examine their adjustment. The results were analyzed using Pearson Product moment correlation while analysis of variance (ANOVA) was used for testing the hypothesis. The result indicates that there is a significant relationship between emotional intelligence and adjustment of these secondary school children, and significant relationship also exists between levels of emotional intelligence and adjustment.

In a conducted by Ogoemeka (2012) on emotional, Intelligence in Ondo and Oyo states. The finding indicated that a positive and significant correlation was found in the scores of emotional intelligence and life adjustment. Parker, Creque, Barnhart, Harris, Majeski, Wood, Bond and Hogan (2004) conducted a study on academic achievement in Huntsville, Alabama. They used the Emotional Quotient Inventory (EQ - i: YV) on 667 adolescents to find out the relationship between emotional intelligence and academic adjustment. Correlation and ANOVA were used to analyze the data collected, and the result reveals that emotional intelligence was a significant predictor of academic success. This study is relevant to the present study because for one to be successful in academic environment, such an individual needs to be academically well adjusted. The present study was anchored on emotional intelligence as a correlate of social and academic adjustment of first-year university students. The students' emotional intelligence, social and academic adjustment anchored on their ability to perceive emotions, and manipulate feelings.

\section{Statement of Problem}

The first-year students are usually confronted with the challenges of identifying, understanding and managing their emotions in positive ways so as to adjust in the university environment, academically and socially. Generally, teachers' and parents demand for better personality and academic progress of their children as they enter the university, these students normally strive to strike a balance between their emotional intelligence and adjustment on campus as well as their social life. Emotional intelligence, as the ability to identify, assess and control one's feeling and that of others, has important role to play on students' academic adjustment. Research revealed that students that are unable to control their emotions will definitely find it difficult to cope academically. This most times leads to frustration on the part of the students, thereby creating difficulties in students' academic adjustment and social interaction.

Maintaining equilibrium between university students' needs and the school environment also poses challenges for students. The university setting presents the challenges of changing lecturers for different courses, classroom, friends, school rules and procedures, performance expectations, deadlines for submission of assignments and term papers, and the difficulty of and interaction with peers. It is evident that emotional intelligence helps in understanding one's emotions, therefore by directing it positively, newly admitted university students may have the ability to cope in their academic work and still maintain a better level of social interaction in their new environments. This study, therefore, is set to find out if there is any relationship between emotional intelligence of newly admitted university students and their academic and social adjustment in the institution. The main aim of this paper is to investigate the relationship between emotional intelligence and 
social and academic adjustment of first-year university students. Specifically, two purposes, two research questions and two hypotheses guided the study. These were indicated as follows

- To determine the relationship between emotional intelligence and social adjustment of first-year university students.

- To ascertain the relationship between emotional intelligence and academic adjustment of first -year university students.

\section{Research Questions}

The following research questions guided the study:

- What is the relationship between emotional intelligence and first -year students' social adjustment?

- What is the relationship between emotional intelligence and first-year students' academic adjustment?

\section{Research Hypotheses}

Two null hypotheses guided this study, and these were tested at 0.05 probability level.

$\mathrm{Ho}_{1} \quad$ There is no significant relationship between emotional intelligence and social adjustment of first -year students.

$\mathrm{Ho}_{2} \quad$ Relationship between emotional intelligence and academic adjustment of first year students will not be significant.

\section{Method}

The study was a correlational research design. A correlational research design is a type of quantitative strategy that is used to determine the nature and scope of relationship that exists between two or more variables being investigated (Ali, 2006; Punch, 2011). This strategy was applicable for this wok due to the fact that the researchers were interested in establishing the relationship existing between emotional intelligence and academic and social adjustment of first-year university students. The study was carried out in South-east geo-political zone of Nigeria comprising Abia, Imo, Anambra, Enugu and Ebonyi States. The geo-political zone is made up of five federal universities that are; Federal University of Technology, Owerri; Micheal Okpara University of Agriculture, Umudike; Nnamdi Azikiwe University, Awka; Federal University Ndufu Alike Ikwo, Abakaliki; and University of Nigeria, Nsukka. These universities are the most sought in the geo-political zone. First -year students from the Faculty of education in these institutions were used for this study. Population of the study consists of the entire first -year students in the Faculty of education from the federal universities in the South-east geo-political zone of Nigeria. The total population is 418 first year students. The choice of this population is to get newly admitted students in the university.

\section{SAMPLE AND SAMPLING TECHNIQUE}

In the process of sampling, the researchers adopted the National Association Small Sample Strategy (1960) as articulated by Krejcie and Morgan (1970), which outlined that when the population of any study is between 400 and 419 respondents, the sample should be between 196 and 200. Therefore, for the fact that the population is 418, the researchers randomly selected 200 students for the present study. Two hundred (200) first-year students were randomly drawn using simple random sampling technique from the Faculty of education from the three out of the five federal universities in the South-east 
geo-political zone. Federal University, Ndufu Alike, Ikwo, and the Federal University of Technology were not part of the study due to the non-existence of faculty of education during the time of the present study. Two tools were used for the study. They are Students' Emotional Intelligence Scale (SEIS) and Students Adjustment Rating Scale (SARS). Students' Emotional Intelligence Scale (SEIS) was adapted from Schutte, Malloff, Hall, Haggertry, Copper, Golden and Dornheim (1998) emotional intelligence scale while the researchers developed Students Adjustment Rating Scale (SARS) was developed after extensively reviewing some related studies. The instruments range from strongly agree (4) to strongly disagree (1) and were used to elicit information about the students' emotional intelligence as well as their social and academic adjustment. The instruments were directly administered to the respondents in other to raise relevant information from them. In answering the research questions Pearson Product Moment Correlation Coefficient was used while Regression Analysis was applied to test the hypotheses at $0.05 \%$ level of significance.

\section{Results AND DISCUSSION}

Table 1: Pearson's Product Moment Correlation Analysis of Students' Emotional Intelligence and their Social Adjustment

\begin{tabular}{|lccccc|}
\hline Variable & $\bar{x}$ & SD & N & r & $\mathbf{R}^{2}$ \\
\hline Emotional Intelligence & 60.23 & 6.22 & & & \\
& & & 200 & 0.65 & 0.42 \\
Social Adjustment & 25.64 & 3.87 & & & \\
\hline
\end{tabular}

$\alpha=0.05, \mathrm{R}^{2}=$ coefficient of determination

In addressing research question one, the scores from students responses on emotional intelligence were correlated with their responses on social adjustment scores. The result in Table 1 shows that the correlation coefficient obtained was 0.65 . This implies that there exist a medium direct positive relationship between emotional intelligence and social adjustment of students. Table 1 also shows that, the coefficient of determination $\left(\mathrm{R}^{2}\right)$ associated with the correlation coefficient of 0.65 was 0.42 . This coefficient of determination $\left(\mathrm{R}^{2}\right)$ indicated that $42 \%$ of students' social adjustment was recorded on their emotional intelligence. This shows that $58 \%$ of the variation in students' social adjustment is attributed to other factors not studied.

Table 2: Pearson's Product Moment Correlation Analysis of Students' Emotional Intelligence and their Academic Adjustment

\begin{tabular}{|lccccc|}
\hline Variable & $\bar{x}$ & $\mathrm{SD}$ & $\mathrm{N}$ & $\mathbf{r}$ & $\mathrm{R}^{2}$ \\
\hline Emotional Intelligence & 60.23 & 6.22 & & & \\
& & & 200 & 0.79 & 0.62 \\
Academic Adjustment & 28.81 & 3.28 & & & \\
\hline
\end{tabular}

$\alpha=0.05, \mathrm{R}^{2}=$ coefficient of determination

To answer research question two, the scores from the responses of the students on emotional intelligence were correlated with their responses on academic adjustment scores. The result in Table 2 shows that the correlation coefficient obtained was 0.79 . This implies that there exist a medium direct positive relationship between emotional intelligence and academic adjustment of students. Table 2 also shows that, the 
coefficient of determination $\left(\mathrm{R}^{2}\right)$ associated with the correlation coefficient of 0.79 was 0.62. This coefficient of determination $\left(\mathrm{R}^{2}\right)$ indicated that $62 \%$ of students' academic adjustment is recorded on their emotional intelligence. This is an indication that $38 \%$ of the variation in students' academic adjustment is attributed to other factors not studied.

\section{Hypothesis 1}

$\mathbf{H}_{01}$ : The relationship between Emotional Intelligence and Social Adjustment of First -Year University Students is not significant.

Table 3: Regression Analysis of Students' Emotional Intelligence and Social Adjustment

\begin{tabular}{|l|l|l|l|l|l|l|}
\hline \multicolumn{2}{|l|}{ Model } & Sum of Squares & $\mathrm{df}$ & Mean Square & $\mathrm{F}$ & Sig. \\
\hline \multirow{4}{*}{} & Regression & 607.465 & 1 & 607.465 & 50.774 & .00 \\
\cline { 2 - 8 } & Residual & 2368.890 & 198 & 11.964 & & \\
\cline { 2 - 7 } & Total & 2976.355 & 199 & & & \\
\hline
\end{tabular}

$\alpha=0.05$

To test hypothesis $1\left(\mathrm{H}_{01}\right)$, regression analysis was used. The result in Table 3 shows that an F-ratio of 50.77 with associated exact probability value of 0.00 was obtained. The probability value of 0.00 was compared with 0.05 , and it was found to be significant because 0.00 is less than 0.05 the level of significance. The students' emotional intelligence significantly predicts students' social adjustment in school, therefore the hypothesis was rejected. This indicates a significant relationship between emotional intelligence and students' social adjustment.

\section{Hypothesis 2}

$\mathbf{H}_{02}$ : There is no significant relationship between Emotional Intelligence and Academic Adjustment of First Year University Students.

Table 4: Regression Analysis of Students' Emotional Intelligence and Academic Adjustment

\begin{tabular}{|l|l|l|l|l|l|l|}
\hline \multicolumn{2}{|l|}{ Model } & Sum of Squares & df & Mean Square & F & Sig. \\
\hline \multirow{6}{*}{} & Regression & 73.952 & 1 & 73.95 & 7.089 & .00 \\
\cline { 2 - 8 } & Residual & 2065.443 & 198 & 10.43 & & \\
\cline { 2 - 7 } & Total & 2139.395 & 199 & & & \\
\hline
\end{tabular}

$\alpha=0.05$

To test hypothesis $2\left(\mathrm{H}_{02}\right)$, regression analysis was also used. An F-ratio of 7.089 with associated probability value of 0.00 was obtained as indicated by the result on Table 4 . This probability value of 0.00 was compared with 0.05 , and it was found to be significant because 0.00 is less than 0.05 set as the level of significance. The students' emotional intelligence significantly predicts their academic adjustment in school therefore the null hypothesis was rejected. The indication was a significant relationship between emotional intelligence and students' academic adjustment.

The results of the study revealed that there exist a direct positive relationship between emotional intelligence and adjustment of first- year university students in the area under study, both academically and socially. The result is in line with Ogoemeka's (2012) finding that there is a positive correlation between emotional intelligence and school adjustment as well as life modification. It also agrees with Parker, Creque, Barnhart, Harris, Majeski, Wood, Bond and Hogan's (2004) finding that emotional intelligence predicts academic 
success. From the result also, there is a significant relationship between emotional intelligence and academic adjustment. The present result with Adeyemo's (2004) that there is a clear relationship between emotional intelligence and academic adjustment. From the result, it was deduced that emotional intelligence significantly predicted students' social adjustment in school. This result is in agreement with Shakuntala and Santosh's (2011) noted that students' emotional intelligence is significantly correlated with their social adaptation.

From all indications, an adjustment is seen here as a process by which individuals attempt to maintain a level of psychological and physiological equilibrium. Parker, Rubin, Earth, Wojslawowics and Buskirk's (2006) also observed that adjustment is the behavioural process by which humans maintain equilibrium among their various needs or between their needs and the obstacles around them. A sequence of modification starts when need arises and stops when it is taken care of. It is evident that emotional intelligence helps in understanding one's emotions. Therefore, using it in a beneficial way, first year university students may have the ability to adjust well in their academic work and still maintain a better level of social interaction in their new environment. The findings of this study, however, revealed that a mid-percentage $(42 \%)$ of students' social adjustment is accounted for by their emotional intelligence while a higher percentage $(62 \%)$ of students' academic adjustment is recorded for their emotional intelligence. The present scope is beyond the variations of other factors that might be responsible.

\section{Concluding Remarks and Recommendations}

Emotional intelligence correlated positively with social and academic adjustment of first year university students. Students' emotional intelligence significantly predicted students' social and academic adjustment in school. Salovey and Mayer's Ability model applied on the developmental task is significant to this study because according to these researchers, emotional intelligence is the process of perceiving feelings, to facilitate thought, and to regulate emotions for the promotion of personal development. Their view is that emotion is a useful source of information that helps one to make sense and navigate the social environment, which can be seen in some adaptive behaviours. The finding of this study is relevant in promoting this theory since emotional intelligence is the ability to manifest certain adaptive attitudes.

Practically, the result of this study will be of benefit to lecturers, school administrators, parents and students. Teachers and school administrators in the university system will be guided on how to help these students to integrate their emotions so as to adjust in the school environment. They will also be aware of the dangers involved when adolescent students are ignorant of their feelings, and should be able to find ways of helping them. The findings will also guide parents in being observant with their adolescent children so as to assist them properly when they are ignorant of their emotions and their consequences. Parents will be guided, as they make demands on their adolescent children about their academic performance for proper adjustment, in the university environment. The students will teach monitor their emotions as they would have a better understanding on how to manage their emotions to enable them to adjust with the university system adjust. This study will add to the already existing literature on emotional intelligence as a correlate of social and academic adjustment of newly admitted university students. The study will equally be of immense benefit to researchers and students in educational, social and other areas of psychology. 


\section{REFERENCES}

Adeyemo, D. A. (2004). The buffering effect of emotional intelligence on the adjustment of secondary school students in transition. Electronic Journal of Research in Educational Psychology, 3(2), 79 - 90.

Akinboye, J.O. (2003). Creativity, Innovation and Success. Ibadan: Striving-Horden Publishers Nigeria

Ali, A. (2006). Fundamentals of Research in Education. Awka, Nigeria: Marks Publishers.

Bandura, A. (1977). Social Learning Theory. Englewood Cliffs, N.J.: Prentice-Hall.

Boulter, L. T. (2002). Self-concept as a predictor of college freshmen academic adjustment. College Students Journal, 36(2), 234 - 246.

Brody, N. (2004). What cognitive intelligence is and what emotional intelligence is not. Psychological Inquiry, 15, $234-238$.

Burgess, T., Crocombe, L., Kelly, J. \& Seet, P. J. (2009). The effect of cultural background on the academic adjustment of the first -year dental students. Ergo, 1(2), 5 - 24.

Collins, W. A., Welsh, D. P. \& Furman, W. (2009). Adolescent romantic relationship. Annual Review of Psychology, 60, $631-650$.

Edward, N. (2003). First impressions last: An innovative approach to induction. Active Learning in Higher Education, 4 (3), 226 - 243.

Enochs, W. K., Renk, K. (2006). Social adjustment of college freshmen: The importance of gender and living environment. College Student Journal, 40(1) 63-72.

Goleman, D. (1995). Emotional Intelligence: Why it can matter more than IQ. New York. Bantam Books.

Grewel, D. \& Salovey, P. (2005). The science of emotional intelligence. Current Direction in Psychological Science, 14(6), 146 - 161.

Hein, S. (2007). EQI. Retrieved Nov. 13, 2013, from emotional intelligence: http://eqi.org/eidefs.htm\#introduction

Krejcie, R. V. \& Morgan, D. W. (1970). Determining Sample Size for Research. Educational and Psychological Measurement. 30, 607 - 610.

Kumar, A.P. (2006). Peer and family relations: A theoretical model for helping students in distress. Unpublished material, University of Malaya, Malaysia.

Kupersmidt, J. B. \& DeRosier, M. E. (2004). How peer problems lead to negative outcomes: An integrative mediational model. In K. A. Dodge and J. B. Kupersmidt, (eds.) Children's peer relations: From development to intervention. Washington, DC: American Psychological Association. pp. 119-138.

Lopes, P. N. \& Salovey, P. (2004). Towards a broader education. In H. J. Walberg, M. C. Wang, J. E. Zins and R. P. Weissberg (Eds.) Building school success on social and emotional learning (pp. 79 - 93). New York: Teachers College Press.

Madhavi, S. W. \& Vijayalaxmi, A. A. (2010). Self - efficacy and emotional intelligence of PG students. Journal of Indian Academy of Applied Psychology, 36(2), 339 - 345.

Mangal, K. S. (2010). Essential of Educational Psychology. New Delhi. PHI.learning Private Limited.

Mayer, J. D. \& Salovey, P. (1990). Emotional Intelligence and the Construction and Regulation of feelings. Applied and Prevention Psychology, 4(3), 197 - 208.

Mayer, J. D. \& Salovey, P. (1997). What is emotional intelligence? In P. Salovey and D. J. Schuster (Eds.) Emotional development and emotional intelligence: Educational Implications (pp. 3 - 31). New York: Basic Books.

Mayer, J. D., Salovey, P. \& Caruso, D. R. (2002). The Mayer - Salovey - Emotional Intelligence Test (MSCEIT): User's manual. Toronto: Multi - Health Systems.

Mayer, J. D., Salovey, P. \& Caruso, D. R. (2004). Emotional intelligence: Theory, Findings and Implications. Psychological Inquiry, 15 (3), 197 - 215.

Mudhovozi, P. (2012). Social and Academic Adjustment of First Year University Students. Journal of Social Science, 33(2) $251-259$. 
National Educational Association Research Bulletin (1960). Sample and Sample Techniques. Vol. 38 pp 99

Ogoemeka, O. H. (2012). A study of the emotional Intelligence lligence and life adjustment of senior secondary school students in Nigeria. The 2012 Orlando International ernational Academic Conference, Orlando Florida, USA, pp. 59 - 66.

Parker, J. D. A., Creque, R. E., Barnhart, D. L., Harris, J. I., Majeski, S. A., Wood, L. M., Bond, B. J. \& Hogan, M. J. (2004). Academic achievement in high school: does emotional intelligence matter? Personality and Individual Differences, 37, 1321 - 1330. www.sciencedirect.com

Parker, J. G., Rubin, K. H., Earth, S. A., Wojslawowics, J. C. \& Buskirk, A. A. (2006). Peer Relationships, Child Development, and Adjustment: A Developmental Psychopathology Perspective. In D. Cicchetti and D. J. Cohen (Eds.) Developmental Psychopathology. NY: Wiley.

Pelletteri, J. (2002). The relationship between emotional intelligence and ego defense mechanisms. Journal of Psychology, 136, $182-194$.

Petrides, K. V. \& Furnham, A. (2006). The role of trait emotional intelligence in a gender - specific model of organizational variables. Journal of Applied Social Psychology, 36(2), 552 - 569.

Punch, K. F. (2011). Introduction to Research Methods in Education. New Delhi. SAGE Publications India Pvt. Ltd

Raju, M. V. \& Rahamtulla, T. K. (2007). Adjustment problems among school students. Journal of the Indian Academy of Applied Psychology, 33(1), 73 - 79.

Robbins, S. P. \& Judge, T. A. (2009). Essentials of organizational behaviour (10 $\left.{ }^{\text {th }} \mathrm{Ed}\right)$. Upper Saddle River, NJ: Prentice Hall.

Roberts, R. D., Zeidner, M. \& Matthews, G. (2001). Does emotional intelligence meet traditional standards for intelligence? Some new data and conclusions. Emotion, 1, $196-231$

Salovey, P. \& Mayer, J. D. (1997). Emotional intelligence. Imagination, Cognition and Personality, 9, 185 $-211$.

Santrock, J. W. (2008). A Topical Approach to life - span Development. New York, NY: McGraw - Hill.

Schutte, N. S., Malouff, J. M., Hall, L. E., Haggertry, D. J., Copper, J. T., Golden, C. J. \& Dornheim, L. (1998). Development and validation of a measure of emotional intelligence. Personality and individual differences, 25, 167 - 177.

Segal, J and Smith M, (2013) Emotional Intelligence (EQ) Five Key Skills for Raising Emotional Intelligence. Retrieved from http://www.helpguide.org/mental/eq5_raising_emotional_intelligence.htm.

Shakuntala, P. \& Santosh, S. (2011). Emotional intelligence and social adaptation of school children. Journal of Psychology, 2(2), 83 - 87.

Tuckman, B. W. \& Monetti, D. M. (2010). Educational Psychology. Belmont, CA: Wadsworth Print.

Van Rooy, D. L. \& Viswesvaran, C. (2004). Emotional intelligence: a Meta - analytic investigation of predictive validity and homological act. Journal of vocational behaviour, 65, 71 - 95

Wang, A., Chen, L., Zhao, B., \& Yan, X. (2006). First year students"e psychological and behavioral adaptation to college: The role of coping strategies and social support. US-China Education Review, 3(5), 51-57. 